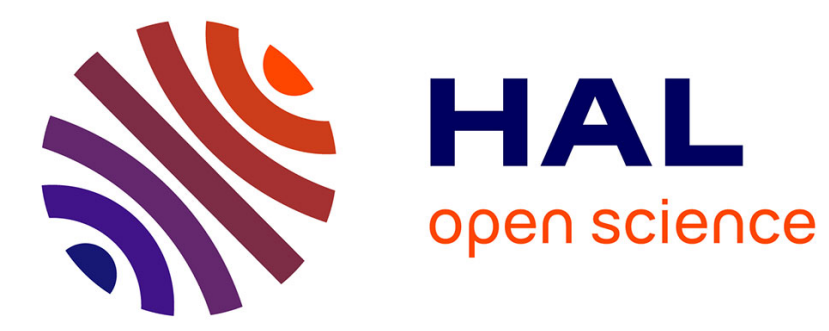

\title{
Strong metal-borane interactions in low-valent cyclopentadienyl Rhodium complexes
}

Maxime Boudjelel, Sonia Mallet-Ladeira, Ghenwa Bouhadir, Didier Bourissou

\section{To cite this version:}

Maxime Boudjelel, Sonia Mallet-Ladeira, Ghenwa Bouhadir, Didier Bourissou. Strong metal-borane interactions in low-valent cyclopentadienyl Rhodium complexes. Chemical Communications, 2019, 55 (85), pp.12837-12840. 10.1039/C9CC06639J . hal-02398800

\section{HAL Id: hal-02398800 https://hal.science/hal-02398800}

Submitted on 8 Dec 2019

HAL is a multi-disciplinary open access archive for the deposit and dissemination of scientific research documents, whether they are published or not. The documents may come from teaching and research institutions in France or abroad, or from public or private research centers.
L'archive ouverte pluridisciplinaire HAL, est destinée au dépôt et à la diffusion de documents scientifiques de niveau recherche, publiés ou non, émanant des établissements d'enseignement et de recherche français ou étrangers, des laboratoires publics ou privés. 
Strong metal-borane interactions in low-valent cyclopentadienyl Rhodium complexes

Maxime Boudjelel, ${ }^{\mathrm{a}}$ Sonia Mallet-Ladeira, ${ }^{\mathrm{b}}$ Ghenwa Bouhadir ${ }^{\mathrm{a}}$ and Didier Bourissou ${ }^{\mathrm{a} *}$

A. CNRS / Universite PAUl SABAtier, LAboratoire Heterochimie Fondamentale et Appliquee (LHFA, UMR 5069). 118 Route de NARBonNe, 31062 Toulouse Cedex 09 (FRANCE). EMAIL : DBOURISS@ ChIMIE.UPS-TLSE.FR

B. Institut de Chimie de Toulouse (FR 2599). 118 Route de Narbonne, 31062 Toulouse Cedex 09 (France).

ABSTRACT. The first examples of half-sandwich Rh(I) complexes stabilized by borane coordination have been prepared and structurally characterized. As substantiated by NMR spectroscopy and singlecrystal x-ray diffraction, the phosphine-borane ligand $i \mathrm{Pr}_{2} \mathrm{P}-\left(\mathrm{O}-\mathrm{C}_{6} \mathrm{H}_{4}\right)-\mathrm{BFxyl} \mathrm{I}_{2} 1\left[\mathrm{Fxyl}=3,5-\left(\mathrm{F}_{3} \mathrm{C}\right)_{2} \mathrm{C}_{6} \mathrm{H}_{3}\right]$ engages in tight $\eta^{3}-B C C$ or $\eta^{1}-B$ coordination, depending on the metal environment.

Transition metal complexes featuring Lewis acid ligands have garnered considerable interest over the last two decades. Initially considered as a chemical curiosity, the ability of Lewis acids to behave as $\sigma$-acceptor (Z-type) ligands has in fact proven quite general. ${ }^{1}$ Besides the fundamental interest associated with TM $\rightarrow$ LA interactions, ${ }^{2}$ Lewis acid ligands open a new way to modulate the properties and reactivity of metal complexes. ${ }^{3}$

Low-valent electron-rich metal fragments are particularly well-suited partners for Lewis acids..$^{1-4}$ In this context, we report here the first example of metal $\rightarrow$ borane interactions in low-valent half-sandwich $\mathrm{Rh}$ complexes. Phosphine cyclopentadienyl $(\mathrm{Cp}) \mathrm{Rh}(\mathrm{l})$ complexes are known to be highly reactive and their faculty to activate a variety of $\sigma$-bonds has been extensively investigated. ${ }^{5-7}$ Due to their strong Lewis basic character, $[(\mathrm{Cp}) \mathrm{Rh}]$ fragments readily engage into $\mathrm{TM} \rightarrow$ LA interactions with heavier group 13 elements. The first such $A$ l and $\mathrm{Ga}$ compounds $\mathbf{A}$ and B were reported by Mayer and Fisher, respectively (Chart 1$).{ }^{8}$ Recently $(C p) L_{2} R h \rightarrow A I X_{3}$ complexes $C\left(L=P M e_{3}\right)$ were also obtained by Braunschweig using transmetallation or disproportionation reactions. ${ }^{9}$ In addition, Rivard showed that heavier group 14 Lewis acids such as $\mathrm{PbCl}_{2}$ can form similar donor-acceptor adducts $\mathbf{D}$. ${ }^{10}$ However, to the best of our knowledge, no related complex has been described so far with boron-based Lewis acids. Conversely, $\mathrm{B}(\mathrm{Fxyl})_{3}$ $\left[\mathrm{Fxyl}=3,5-\left(\mathrm{F}_{3} \mathrm{C}\right)_{2} \mathrm{C}_{6} \mathrm{H}_{3}\right]$ was found to react at the $\mathrm{Cp}$ ring to give the zwitterionic $\mathrm{Rh}(\mathrm{III})$ hydride species $\mathrm{E}^{10}$
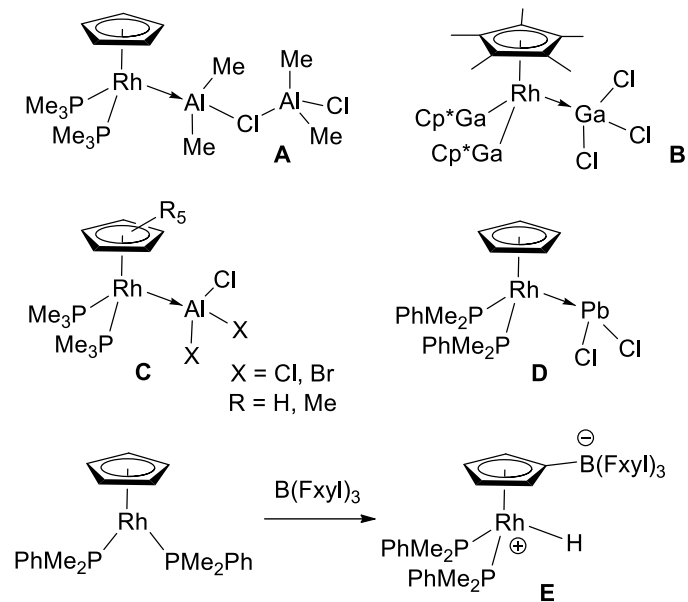

Chart 1 Low-valent cyclopentadienyl rhodium complexes stabilised by $\mathrm{Rh} \rightarrow \mathrm{LA}$ interactions.

Because of their chelating character and modulable structure, ambiphilic phosphine-boranes are particularly efficient in supporting $\mathrm{M} \rightarrow \mathrm{B}$ interactions. ${ }^{11}$ In this context, we took advantage here of the phosphine-borane $i \mathrm{Pr}_{2} \mathrm{P}-$ $\left(o-\mathrm{C}_{6} \mathrm{H}_{4}\right)-\mathrm{BFxyl}_{2}$ 1. As shown in our previous work, ${ }^{12}$ compound $\mathbf{1}$ adopts a closed structure with strong but geometrically constrained $\mathrm{P} \rightarrow \mathrm{B}$ interaction. As a result, it behaves as a dormant Lewis pair and proved to efficiently catalyse the dehydrogenation of a variety of amine and diamine-boranes under mild conditions. Here, $(C p) R h$ complexes of 1 have been investigated and the borane moiety was found to engage in $\eta^{3}-B C C$ and $\eta^{1}-B$ coordination, as substantiated by NMR and X-ray diffraction analyses.

The direct coordination of 1 to the [(Cp)Rh] fragment was first attempted by reacting it with the ethylene precursor $\left[\left(\eta^{5}-\mathrm{Cp}\right) \mathrm{Rh}\left(\eta^{2}-\mathrm{C}_{2} \mathrm{H}_{4}\right)_{2}\right]$ in refluxing toluene. The solution turns progressively dark purple but the displacement of ethylene at $\mathrm{Rh}$ by the phosphine-borane was very slow (it is incomplete even after 10 days) and not 
clean, several side-products being formed concomitantly. The desired complex $\mathbf{2}$ was obtained much more efficiently via a two-step procedure (Scheme 1). ${ }^{13}$ The (P,B) ligand 1 was first treated with the dimeric $\mathrm{Cl}$-bridged $\mathrm{Rh}$ precursor $\left[\mathrm{Rh}\left(\eta^{2}-\mathrm{C}_{2} \mathrm{H}_{4}\right)_{2}(\mu-\mathrm{Cl})\right]_{2}$ in toluene. Within a few hours at room temperature, the mixture takes a blood red color. One equivalent of TICp was added afterwards. The solution rapidly turned dark purple and TICl crashed out of solution. ${ }^{31} \mathrm{P}\left\{{ }^{1} \mathrm{H}\right\}$ NMR monitoring revealed a complete and clean reaction within 4 hours of time. According to High Resolution Mass Spectrometry (HRMS) $(\mathrm{m} / \mathrm{z}=798.0980)$, the formed complex 2 results from the coordination of the phosphine-borane 1 to the $[(\mathrm{Cp}) \mathrm{Rh}]$ fragment. The ${ }^{31} \mathrm{P}\left\{{ }^{1} \mathrm{H}\right\}$ NMR spectrum shows a doublet signal at $\delta 79.6 \mathrm{ppm}$ with a diagnostic ${ }^{1} J_{\mathrm{PRh}}$ coupling constant $(173 \mathrm{~Hz})$. No ${ }^{11} \mathrm{~B}$ NMR signal could be resolved, but the participation of the $\mathrm{B}(\mathrm{Fxyl})_{2}$ moiety in the coordination was clearly apparent from the loss of symmetry of the Fxyl groups observed in the ${ }^{19} \mathrm{~F},{ }^{1} \mathrm{H}$ and ${ }^{13} \mathrm{C}$ NMR spectra. The ${ }^{19} \mathrm{~F}$ NMR spectrum displays three $\mathrm{CF}_{3}$ signals of relative integrations $1: 1: 2$ at $\delta$ $-64.20,-63.99$ and $-63.06 \mathrm{ppm}$ indicating that the two aryl groups are not interchanging and that only one freely rotates. One of the ortho $\mathrm{C}-\mathrm{H}$ group of the dessymetrized $\mathrm{Fxyl}$ group displays very shielded ${ }^{1} \mathrm{H}$ and ${ }^{13} \mathrm{C}$ NMR signals ( $\delta 3.53$ and $61.43 \mathrm{ppm}$, respectively), as deduced from $\mathrm{HSQC}{ }^{19} \mathrm{~F} /{ }^{13} \mathrm{C}$ and HSQC ${ }^{1} \mathrm{H} /{ }^{13} \mathrm{C}$ experiments. ${ }^{13}$ These features suggest that one of the Fxyl group is engaged in direct unsymmetric coordination to Rh.

Crystals of $\mathbf{2}$ suitable for X-ray diffraction analysis were obtained by slow evaporation of a concentrated pentane solution at room temperature. The complex adopts a piano-stool structure (Fig. 1). Besides phosphorus, the phosphine-borane 1 binds to Rh via the boron center and one of the Fxyl ring resulting in tight $\eta^{3}$-BCC coordination. ${ }^{14}$ The Rh-B distance is short at 2.409(4) $\AA$ and falls in the same range than those we observed in square-pyramidal diphosphine-borane $\mathrm{Rh}(\mathrm{I})$ complexes. ${ }^{15}$ Consistently, the boron environment is pyramidalized (the sum of C-B-C bond angles $\Sigma \alpha \mathrm{B}$ is $353.6^{\circ}$ ). The ipso carbon atom and one of the ortho carbon atoms of a Fxyl group also show short contacts to Rh at 2.191(4) and 2.255(4) $\AA$, respectively. Most noticeable is the pyramidalization of the respective $\mathrm{C}_{\text {ortho }}$ atom $\left(\mathrm{H}_{\text {ortho }}\right.$ deviates out of the Fxyl plane by $0.333 \AA$ ) ${ }^{16}$ and the partial dearomatization of the Fxyl ring (as apparent from the alternation of short and long CC bonds). ${ }^{17}$

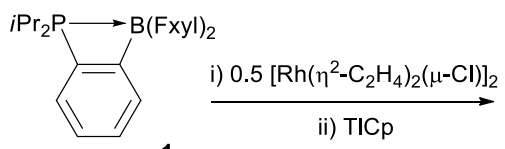

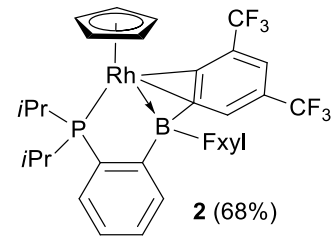

Scheme 1 Synthesis of the $(C p) R h(P, B)$ complex 2.

The highly Lewis acidic $\mathrm{BFxyl}_{2}$ moiety of $\mathbf{1}$ is thus engaged in tight $\eta^{3}-\mathrm{BCC}$ coordination, providing thermodynamic and kinetic stability to the low-valent $[(C P) R h(P, B)]$ complex 2. Of note, Emslie and co-workers previously reported $\eta^{3}$-BCC coordination of a BPh moiety to Rh in the heterobimetallic complex [(TXPB)Rh( $\mu$-CO $\left.)_{2} \mathrm{Fe}(\mathrm{CO}) \mathrm{Cp}\right]$, where TXPB is a rigid phosphine-borane derived from thioxanthene. ${ }^{18}$ The found $\mathrm{Rh}-\mathrm{B}, \mathrm{Rh}-\mathrm{C}_{\text {ipso }}$ and $\mathrm{Rh}-\mathrm{C}_{\text {ortho }}$ distances [2.63(2), 2.33(2) and 2.46(2) $\AA$, respectively] are all substantially longer than in 2, indicating weaker coordination of the Baryl moiety. The difference between the two systems is also apparent in solution by NMR. In the [(TXPB)Rh( $\mu$ $\mathrm{CO})_{2} \mathrm{Fe}(\mathrm{CO}) \mathrm{Cp}$ ] complex, broad signals were observed at room temperature for the $\mathrm{BPh}_{2}$ moiety due to fluxional behavior. ${ }^{19}$ High-field ${ }^{1} \mathrm{H}$ NMR signals diagnostic of aryl coordination and loss of symmetry were observed at low temperature $\left(-75^{\circ} \mathrm{C}\right)$. In contrast, complex 2 adopts an unsymmetric frozen structure at room temperature and according to variable-temperature ${ }^{19} \mathrm{~F}$ NMR experiments upon heating, ${ }^{13}$ the two $\mathrm{CF}_{3}$ signals of the coordinated Fxyl group coalesce only at $c a 80^{\circ} \mathrm{C}$. The activation barrier of this process, which may involve the slippage of the Fxyl ring or rotation around the $\mathrm{B}-\mathrm{C}_{\text {ipso }}$ bond, was estimated to $18.0 \mathrm{kcal} / \mathrm{mol} .^{13}$ Note that the two Fxyl groups remain inequivalent up to the highest accessible temperature, ie $100^{\circ} \mathrm{C}$. 


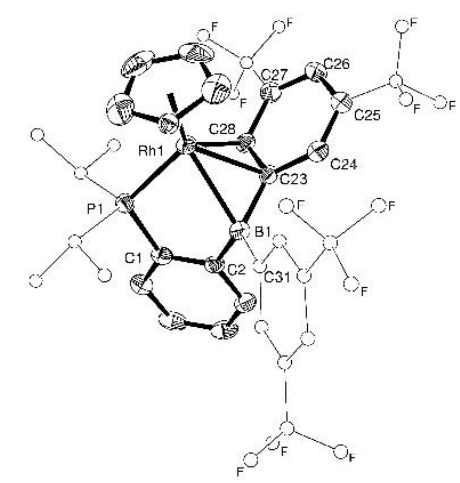

Fig 1 Molecular structure 2 as determined by X-Ray diffraction analysis. Ellipsoids are shown at 50\% probability; iPr and free Fxyl are simplified, and $\mathrm{H}$ atoms omitted for clarity. Selected bond distances (Å) and angles ( ${ }^{\circ}$ ): P1-Rh1 2.282(1), Rh1-B1 2.409(4), Rh1-C23 2.191(4), Rh1-C28 2.255(4), C23-C28 1.439(6), C28C27 1.450(5), C27-C26 1.355(5), C26-C25 1.420(6), C25-C24 1.359(5), C24-C23 1.440(5), C2-B1-C31 117.3(3), C31-B1-C23 120.3(3), C23-B1-C2 116.0(3).

The possibility to displace the Fxyl group from $\mathrm{Rh}$ and to shift the coordination mode of the borane moiety from $\eta^{3}-\mathrm{BCC}$ to $\eta^{1-B}$ was then investigated. To this end, complex 2 was reacted with donor ligands, ie an alkene, a phosphine and an isonitrile (Scheme 2). Complex $\mathbf{2}$ proved completely inert towards ethylene, even after prolonged heating under pressure ( 4 bars, $50^{\circ} \mathrm{C}, 24$ hours). With $\mathrm{PMe}_{3}$, some reaction occurred, but ${ }^{31} \mathrm{P}$ NMR monitoring showed very slow conversion of 2. Using a large excess of phosphine, the formation of the $\left[(C p)\left(\mathrm{Me}_{3} P\right) R h(P, B)\right]$ complex 3 reached completion after 11 days at room temperature. Comparatively, the reaction of 2 with CNXYl [XYl $=2,6-\left(\mathrm{H}_{3} \mathrm{C}\right)_{2} \mathrm{C}_{6} \mathrm{H}_{3}$ ] was much faster and the ensuing complex 4 was obtained in high yield (85\%) within 12 hours using only a slight excess of isonitrile. ${ }^{20}$ The ${ }^{31} \mathrm{P}\left\{{ }^{1} \mathrm{H}\right\}$ NMR signature of complex $\mathbf{3}$ is characteristic with two doublets of doublets at $\delta-2.45$ and $81.22 \mathrm{ppm}$ featuring large ${ }^{1} J_{\mathrm{PRh}}$ couplings (170 and $180 \mathrm{~Hz}$, respectively) as well as ${ }^{2} J_{\mathrm{PP}}$ coupling $(50.3 \mathrm{~Hz})$. Complex 4 gives a doublet at $\delta 84.5 \mathrm{ppm}\left({ }^{1} J_{\mathrm{PRh}} 170 \mathrm{~Hz}\right)$, very similar to that of 2. Distinct ${ }^{11} \mathrm{~B}$ NMR signals were observed for complexes 3 and 4 at $\delta 4.6$ and $8.8 \mathrm{ppm}$, respectively. Combined with the inequivalence and free rotation of the two Fxyl groups (as apparent from the ${ }^{19} \mathrm{~F},{ }^{1} \mathrm{H}$ and ${ }^{13} \mathrm{C}$ NMR spectra), this is indicative of $\eta^{1-}$ coordination via $\mathrm{Rh} \rightarrow \mathrm{B}$ interaction of the borane moiety. The NC stretch of the isonitrile in complex $4\left(2119 \mathrm{~cm}^{-1}\right)$ is very close to that of free XyINC $\left(2122 \mathrm{~cm}^{-1}\right)$.

To further analyse the bonding situation in $\mathbf{3}$ and $\mathbf{4}$, single crystals were grown and X-ray diffraction studies were performed (Figure 2). Both complexes adopt piano-stool structures with $\mathrm{P} \rightarrow \mathrm{Rh} \rightarrow \mathrm{B}$ bridging coordination of the ambiphilic ligand. Upon coordination of $\mathrm{PMe}_{3}$ and $\mathrm{CNXYl}$ to $\mathrm{Rh}$, the borane shifts from $\eta^{3}-\mathrm{BCC}$ to $\eta^{1}-\mathrm{B}$ coordination. This is accompanied by some shortening of the Rh-B distance [from 2.409(4) $\AA$ in 2, to 2.377(3) and 2.349(3) $\AA$ in 3 and 4, respectively] and further pyramidalization of the boron environment $\left(\Sigma \alpha B=353.6^{\circ}\right.$ in 2 vs 332.0 and $333.0^{\circ}$ in 3 and 4, respectively). Conversely, the $\mathrm{P}-\mathrm{Rh}-\mathrm{B}$ bite angle remains almost unchanged upon binding of the additional donor ligand to $\mathrm{Rh}\left[77.2(1)^{\circ}\right.$ in $\mathbf{2}$ vs 80.90(9) and 79.83(6) in $\mathbf{3}$ and 4, respectively].

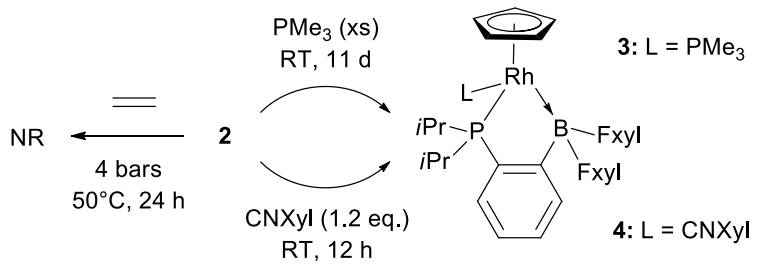

Scheme 2 Synthesis of the $[(\mathrm{Cp}) \operatorname{LRh}(\mathrm{P}, \mathrm{B})]$ complexes $\mathbf{3}$ and $\mathbf{4}\left(\mathrm{Xyl}=2,6-\left(\mathrm{H}_{3} \mathrm{C}\right)_{2} \mathrm{C}_{6} \mathrm{H}_{3}\right)$.

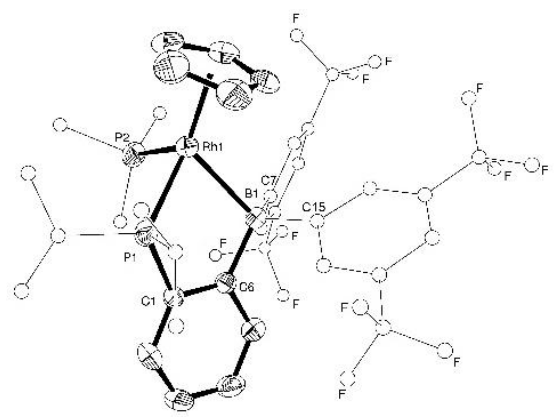




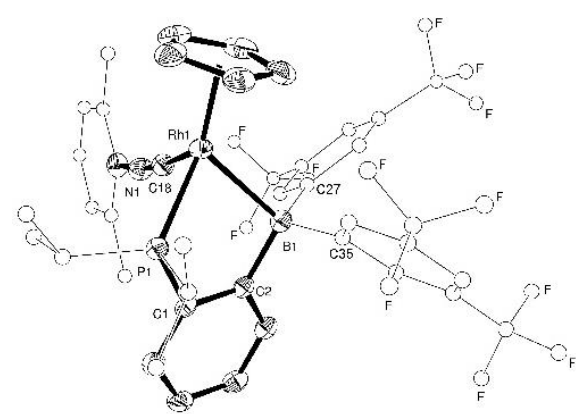

Fig 2 Molecular structure 3 (top) and $\mathbf{4}$ (bottom) as determined by X-Ray diffraction analysis. Ellipsoids are shown at $50 \%$ probability; $\mathrm{Pr}$, Fxyl and Xyl are simplified, and $\mathrm{H}$ atoms omitted for clarity. Selected bond distances $(\AA \AA)$ and angles $\left({ }^{\circ}\right)$. 3: P1-Rh1 2.254(1), Rh1-P2 2.266(1), Rh1-B1 2.377(3), C6-B1-C7 114.0(3), C7-B1-C15 111.1(3), C15-B1-C6 106.9(3). 4: P1-Rh1 2.272(1), Rh1-B1 2.349(3), Rh1-C18 1.893(2), C2-B1-C27 113.4(2), C27-B1-C35 110.6(2), C35-B1-C2 109.0(2).

Finally, to assess the withdrawing effect of the $\mathrm{Rh} \rightarrow \mathrm{B}$ interaction, we studied the reaction of $\mathbf{2}$ with $\mathrm{CO}$ with the aim to obtain the $[(\mathrm{CP})(\mathrm{OC}) \mathrm{Rh}(\mathrm{P}, \mathrm{B})]$ complex $\mathbf{5}$ (Scheme 3). According to ${ }^{31} \mathrm{P}\left\{{ }^{1} \mathrm{H}\right\} \mathrm{NMR}$ spectroscopy, the reaction was slow at room temperature but proceeded readily at $75^{\circ} \mathrm{C}$ under 3.5 bars of pressure. The NMR features of the $(P, B)$ ligand in 5 ( ${ }^{31} \mathrm{P}: \delta 84.5 \mathrm{ppm}$, doublet, ${ }^{1} \mathrm{JRh}_{\mathrm{PRh}}=173 \mathrm{~Hz} ;{ }^{11} \mathrm{~B}: \delta 14.0 \mathrm{ppm}$; symmetry of the Fxyl groups in ${ }^{19} \mathrm{~F},{ }^{1} \mathrm{H}$ and ${ }^{13} \mathrm{C}$ ) are indicative of $\mathrm{P} \rightarrow \mathrm{Rh} \rightarrow \mathrm{B}$ bridging coordination, by analogy to complexes 3 and 4 . In addition, the ${ }^{13} \mathrm{C}$ NMR signal observed at $\delta 192.4 \mathrm{ppm}$ (doublet of doublet due to ${ }^{1} J_{\mathrm{CRh}}$ and ${ }^{2} J_{\mathrm{CP}}$ couplings of 81.6 and $21.0 \mathrm{~Hz}$, respectively) is diagnostic for the coordination of $\mathrm{CO}$ to Rh. The $v(\mathrm{CO})$ stretching frequency of complex 5 is found at $2011 \mathrm{~cm}^{-1}$ in the infrared spectrum, shifted to higher wavenumbers by as much as $50-100 \mathrm{~cm}^{-1}$ compared to those of related Rh complexes free of borane. ${ }^{21,22}$ In line with relatively strong $\mathrm{Rh} \rightarrow \mathrm{B}$ interaction, the highly Lewis acidic $\mathrm{BF} x \mathrm{l} \mathrm{I}_{2}$ borane thus depletes electron density from Rh in complex $\mathbf{5}$ and thereby significantly weakens the $\mathrm{Rh} \rightarrow \mathrm{CO}$ backdonation.

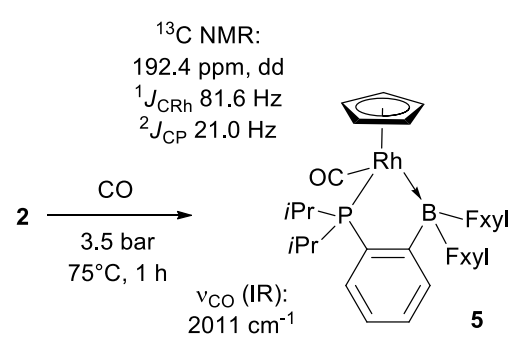

Scheme 3 Synthesis and key spectroscopic data of the $[(C p)(O C) R h(P, B)]$ complex 5.

In summary, the first examples of low-valent half-sandwich Rh complexes stabilized by borane coordination have been prepared and structurally characterized. The phosphine-borane ligand $\mathbf{1}$ is able to stabilize both $[(\mathrm{Cp}) \mathrm{Rh}]$ and $\left[\mathrm{Cp}(\mathrm{L}) \mathrm{Rh}\right.$ ] fragments thanks to the faculty of the $\mathrm{BFxyl} \mathrm{I}_{2}$ moiety to shift from $\eta^{3}-\mathrm{BCC}$ to $\eta^{1}-\mathrm{B}$ coordination. Shifts in the coordination mode of aryl-boranes to transition metals are very rare. Of note, Cowie and Emslie recently evidenced exchanges between $\eta^{3}-B C C, \eta^{2}-B C$ and $\eta^{1}-B$ coordination in platinum(0) complexes of a $B P h_{2}$-appended diphosphine. ${ }^{23}$ The fact that $i \mathrm{Pr}_{2} \mathrm{P}-\left(o-\mathrm{C}_{6} \mathrm{H}_{4}\right)-\mathrm{BFxyl}{ }_{2}$ displays such flexibility in complexes $\mathbf{2}-\mathbf{5}$, despite the tight $\eta^{3}-\mathrm{BCC}$ and $\eta^{1}-B$ coordination to $R h$, is noteworthy.

The unique properties of the Fxyl group ${ }^{24}$ make phosphine-boranes such as $\mathbf{1}$ very appealing ambiphilic ligands. Future work in our group will aim to develop further this chemistry, in particular reactivity and catalysis involving $\mathrm{M} \rightarrow$ B cooperation. $^{3}$

Financial support from the Centre National de la Recherche Scientifique and the Universite de Toulouse is acknowledged. We thank Pierre Lavedan (ICT, Toulouse) for helpful assistance with the HSQC $\left\{{ }^{13} \mathrm{C} ;{ }^{19} \mathrm{~F}\right\}$ and variable temperature NMR experiments.

1 (a) F. G. Fontaine, J. Boudreau and M. H. Thibault, Eur. J. Inorg. Chem., 2008, 5439-5454; (b) H. Braunschweig, R. D. Dewhurst and A. Schneider, Chem. Rev., 2010, 110, 3924-3957; (c) A. Amgoune and D. Bourissou, Chem. Commun., 2011, 47, 859-871; (d) H. Kameo and H. Nakazawa, Chem. - An Asian J., 2013, 8, 1720-1734.

2 (a) G. Bouhadir and D. Bourissou, Struct. Bond. 2017, 171, 141-202; (b) H. Kameo and H. Nakazawa, Chem. Rec., 2017, 17, 268-286.

3 (a) M. Devillard, G. Bouhadir and D. Bourissou, Angew. Chem. Int. Ed., 2015, 54, 730-732; (b) G. Bouhadir and D. Bourissou, Chem. Soc. Rev., 2016, 45, 1065-1079; (c) G. Bouhadir and D. Bourissou, in Ligand Design in Metal Chemistry: Reactivity and Catalysis, ed. M. Stradiotto and R. J. Lundgren, John Wiley \& Sons, 2016, 237-269; (d) A. Maity and T. S. Teets, Chem. Rev., 2016, 116, 8873-8911; (e) G. R. Owen, Chem. Commun., 2016, 52, 10712-10726; 
(f) W. Guan, G. Zeng, H. Kameo, Y. Nakao and S. Sakaki, Chem. Rec., 2016, 16, 2405-2425; $(g)$ J. S. Jones and F. P. Gabbaï, Acc. Chem. Res., 2016, 49, 857-867; (h) D. You and F. P. Gabbaï, Trends Chem., 2019, 1, 485-496.

4 B. R. Barnett and J. S. Figueroa, Chem. Commun., 2016, 52, 13829-13839.

5 For $\mathrm{C}\left(\mathrm{sp}^{2}\right)-\mathrm{H}$ and $\mathrm{C}\left(\mathrm{sp}^{2}\right)-\mathrm{F}$ bonds, see: (a) W. D. Jones and F. J. Feher, Acc. Chem. Res., 1989, 22, 91-100; (b) S. T. Belt, S. B. Duckett, M. Helliwell and R. N. Perutz, J. Chem. Soc., Chem. Commun., 1989, 73, 928-930; (c) A. D. Selmeczy, W. D. Jones, M. G. Partridge and R. N. Perutz, Organometallics, 1994, 13, 522-532; (d) W. D. Jones, L. Dong and A. W. Myers, Organometallics, 1995, 14, 855-861; (e) S. T. Belt, M. Helliwell, W. D. Jones, M. G. Partridge and R. N. Perutz, J. Am. Chem. Soc., 1993, 115, 1429-1440; (f) T. Braun and F. Wehmeier, Eur. J. Inorg. Chem., 2011, 613-625.

6 For H-B, B-B, H-Si bonds, see: M. V. Câmpian, J. L. Harris, N. Jasim, R. N. Perutz, T. B. Marder and A. C. Whitwood, Organometallics, 2006, 25, 5093-5104.

7 For $\mathrm{R}_{\mathrm{F}}-\mathrm{I}$ bonds, see: (a) C. J. Bourgeois, R. P. Hughes, T. L. Husebo, J. M. Smith, I. M. Guzei, L. M. Liable-Sands, L. N. Zakharov and A. L. Rheingold, Organometallics, 2005, 24, 6431-6439; (b) J. Gil-Rubio, J. Guerrero-Leal, M. Blaya, J. Vicente, D. Bautista and P. G. Jones, Organometallics, 2012, 31, 1287-1299; (c) M. Blaya, D. Bautista, J. Gil-Rubio and J. Vicente, Organometallics, 2017, 36, 1245-1258.

8 (a) J. M. Mayer and J. C. Calabrese, Organometallics, 1984, 3, 1292-1298; (b) T. Steinke, C. Gemel, M. Cokoja, M. Winter and R. A. Fischer, Dalton Trans., 2005, 46, 55-62.

9 (a) J. Bauer, H. Braunschweig and K. Radacki, Chem. Commun., 2012, 48, 10407-10409; (b) A. Hofmann, A. Lamprecht, J. O. C. Jiménez-Halla, T. Tröster, R. D. Dewhurst, C. Lenczyk and H. Braunschweig, Chem. - Eur. J., 2018, 24, 11795-11802.

10 A. K. Swarnakar, M. J. Ferguson, R. McDonald and E. Rivard, Dalton Trans., 2016, 45, 6071-6078.

11 (a) G. Bouhadir, A. Amgoune and D. Bourissou, Adv. Orgnomet. Chem., 2010, 58, 1-107; (b) A. Amgoune, G. Bouhadir and D. Bourissou, in Frustrated Lewis Pairs II, Topics in Current Chemistry, ed. D. W. Stephan and G. Erker, Springer, 2013, 281-311.

12 M. Boudjelel, E. D. Sosa Carrizo, S. Mallet-Ladeira, S. Massou, K. Miqueu, G. Bouhadir and D. Bourissou, ACS Catal., $2018,8,4459-4464$.

13 See supporting information for details.

14 For a recent review on multi-center $\mathrm{BC}_{n}$ coordination of aryl-boranes to transition metals, see: D. J. H. Emslie, B. E. Cowie and K. B. Kolpin, Dalton Trans., 2012, 41, 1101-1117.

15 (a) S. Bontemps, H. Gornitzka, G. Bouhadir, K. Miqueu and D. Bourissou, Angew. Chem. Int. Ed., 2006, 45, 16111614; (b) S. Bontemps, M. Sircoglou, G. Bouhadir, H. Puschmann, J. A. K. Howard, P. W. Dyer, K. Miqueu and D. Bourissou, Chem. - Eur. J., 2008, 14, 731-740.

16 The $\mathrm{H}$ atom bonded to the $\mathrm{C}_{\text {ortho }}$ atom coordinated to $\mathrm{Rh}$ was localized unequivocally in the difference Fourier map.

17 Two $\left(\mathrm{Cp} / \mathrm{Cp} \mathrm{p}^{*}\right)$ complexes stabilized by $\eta^{2}$-CC coordination of pyridine ligands have been recently described, see $(a)$ B. Procacci, R. J. Blagg, R. N. Perutz, N. Rendón and A. C. Whitwood, Organometallics, 2014, 33, 45-52; (b) D. Lionetti, V. W. Day, B. Lassalle-Kaiser and J. D. Blakemore, Chem. Commun., 2018, 54, 1694-1697.

18 S. R. Oakley, K. D. Parker, D. J. H. Emslie, I. Vargas-Baca, C. M. Robertson, L. E. Harrington and J. F. Britten, Organometallics, 2006, 25, 5835-5838.

19 Fluxional behaviour has been systematically observed at room temperature for TM complexes featuring $\eta^{3}-\mathrm{BCC}$ coordinated BPh moieties.

20 The faster reactivity of CNXyl vs $\mathrm{PMe}_{3}$ suggests that the displacement of the Fxyl group at Rh occurs via an associative process.

21 The $v(\mathrm{CO})$ bands reported for $\left[\left(\eta^{5}-\mathrm{Ar}\right) \mathrm{Rh}\left(\mathrm{PR}_{3}\right)(\mathrm{CO})\right]$ complexes $(\mathrm{Ar}=\mathrm{Cp}, \mathrm{Cp} *$ or indenyle) fall in the range 1907-1960 $\mathrm{cm}^{-1}$ : (a) J. A. Klang and D. B. Collum, Organometallics, 1988, 7, 1532-1537; (b) L. Lefort, T. W. Crane, M. D. Farwell, D. M. Baruch, J. A. Kaeuper, R. J. Lachicotte and W. D. Jones, Organometallics, 1998, 17, 3889-3899; (c) E. Bleuel, O. Gevert, M. Laubender and H. Werner, Organometallics, 2000, 19, 3109-3114.

22 For $\mathrm{Rh}(\mathrm{III})$ complexes, the $v(\mathrm{CO})$ band is further shifted and is typically found at $2040-2060 \mathrm{~cm}^{-1}$, see: ref $7 \mathrm{~b}$ and $(a)$ H. Werner, M. Steinmetz, K. Peters and H. G. von Schnering, Eur. J. Inorg. Chem., 1998, 1605-1617; (b) Y. Kataoka, A. Shibahara, T. Yamagata and K. Tani, Organometallics, 2001, 20, 2431-2433.

23 B. E. Cowie and D. J. H. Emslie, Chem. - Eur. J., 2014, 20, 16899-16912.

24 It is strongly electron-withdrawing and brings remote steric hindrance. For pioneering studies on $\mathrm{R}_{2} \mathrm{P}\left(\mathrm{CH}_{2}\right)_{n} \mathrm{~B}(\mathrm{Fxyl})_{2}$ derivatives, see: (a) K. Samigullin, I. Georg, M. Bolte, H. W. Lerner and M. Wagner, Chem. - Eur. J., 2016, 22, 34783484. (b) L. Wang, K. Samigullin, M. Wagner, A. C. McQuilken, T. H. Warren, C. G. Daniliuc, G. Kehr and G. Erker, Chem. - Eur. J., 2016, 22, 11015-11021. 